\title{
Flotation Behavior of Complex Sulfide Ores in the Presence of Biodegradable Polymeric Depressants
}

\author{
Muhammad Badar Hayat, ${ }^{1,2}$ Lana Alagha, ${ }^{1}$ and Syed Mohammad Sannan ${ }^{3}$ \\ ${ }^{1}$ Department of Mining and Nuclear Engineering, Missouri University of Science and Technology, Rolla, MO 65401, USA \\ ${ }^{2}$ Mining Engineering Department, University of Engineering and Technology, Lahore, Pakistan \\ ${ }^{3}$ Department of Mechanical and Aerospace Engineering, Missouri University of Science and Technology, Rolla, MO 65401, USA
}

Correspondence should be addressed to Lana Alagha; Alaghal@mst.edu

Received 8 February 2017; Revised 22 April 2017; Accepted 14 May 2017; Published 12 June 2017

Academic Editor: Miriam H. Rafailovich

Copyright (C) 2017 Muhammad Badar Hayat et al. This is an open access article distributed under the Creative Commons Attribution License, which permits unrestricted use, distribution, and reproduction in any medium, provided the original work is properly cited.

\begin{abstract}
In this study, chitosan polymer was tested as a potential selective green depressant of pyrite in the bulk flotation of galena ( $\mathrm{PbS}$ ) and chalcopyrite $\left(\mathrm{CuFeS}_{2}\right)$ from sphalerite $(\mathrm{ZnS})$ and pyrite $\left(\mathrm{FeS}_{2}\right)$ using sodium isopropyl xanthate as a collector and 4-methyl-2pentanol (MIBC) as a frother. Flotation tests were carried out in a D12-Denver flotation laboratory cell in the presence and absence of chitosan and/or sodium cyanide depressant which is commercially used as pyrite depressant in sulfide mineral flotation process. Flotation recoveries and concentrate grades (assay) were studied as a function of polymer concentration and flotation time. It was found that at $50 \mathrm{~g} / \mathrm{ton}$, chitosan depressed $5.6 \%$ more pyrite as compared to conventional depressant NaCN at its optimum dosage. Furthermore, the measured assay values of pyrite in concentrates dropped by $\sim 1.2 \%$ when NaCN depressant was replaced with chitosan polymer. Zeta potential measurements of galena, chalcopyrite, sphalerite, and pyrite suspensions before and after chitosan's addition revealed that the polymer has preferential adsorption on pyrite minerals as compared to other sulfide minerals specially galena. Results obtained from this work show that chitosan polymer has a promising future as a biodegradable alternative to sodium cyanide for the purpose of depressing pyrite in sulfide minerals flotation.
\end{abstract}

\section{Introduction}

Froth flotation has found extensive use in the mineral processing industry especially in treating low grade ores. Froth flotation process exploits the difference in surface hydrophobicity of mineral particles. In this process, hydrophobic mineral particles are selectively captured and carried by air bubble to the froth product, whereas hydrophilic minerals are discharged as tailings or reject. Polymers have received considerable attention due to their tunability and the opportunity that they provide to enhance the flotation performance at a lower cost [1]. A good example is polyacrylamide-based polymers that are widely used in ore flotation processes as multifunctional reagents. Depending on the integrated functional groups, polyacrylamides and their derivatives are being used as collectors, depressants, activators, or modifiers. Hybrid polyacrylamide polymer (Hy-PAM) was successfully applied in fine coal flotation to enhance the combustible recovery and reduce the ash contents of coal concentrates [2].

Base metals such as copper, lead, and zinc are mainly extracted from sulfide ores. Mostly these base metals tend to exist together in an ore. Flotation process is widely used to separate these minerals in sulfide ores [1]. A wide range of chemical reagents are used in the flotation process to separate the different minerals. Most of these reagents such as cyanides are toxic in nature and cause detrimental negative impact on the environment [3].

In the early nineteenth century cyanide was discovered to be a good depressant for Ferro and zinc sulfide minerals. Since that time cyanides have been used extensively as pyrite $\left(\mathrm{FeS}_{2}\right)$ depressant in sulfide mineral flotation. Pyrite can easily float to the concentrate and deteriorate its grade and cause several problems in the subsequent downstream processes. However, cyanides depressants end up precipitating in the 


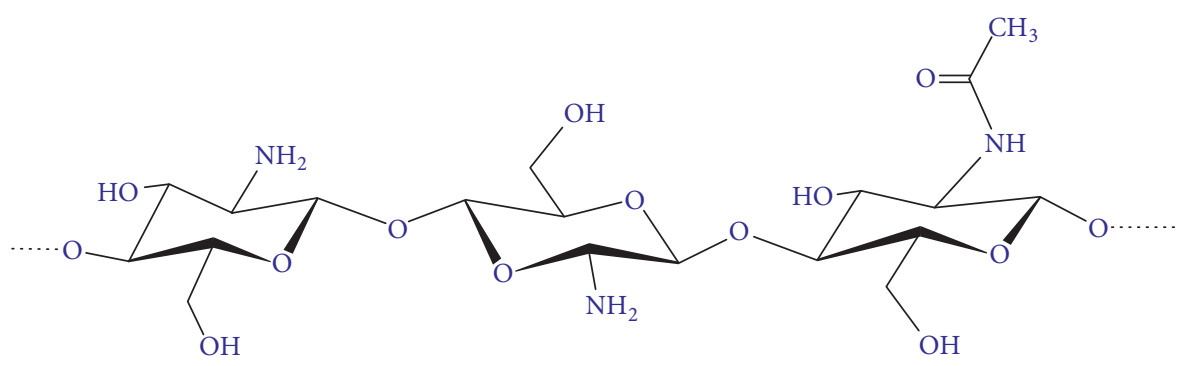

FIGURE 1: Structure of chitosan polymer.

tailing dumps. These tailing dumps can render the local underground water resources poisonous. As these cyanides are toxic and hazardous, their replacement is highly desirable.

In sulfide mineral flotation, Polymers have been used as potential candidates to replace hazardous reagents. Polyacrylamide polymers (PAMs) with different functional groups exhibited depressing ability for ferrous sulfide minerals such as pyrite [4]. Recently a biodegradable polymer chitosan has also shown a promising depressing ability for ferrous sulfide minerals. Chitosan has a lot of advantages over $\mathrm{NaCN}$ because it is abundant, biodegradable, and bio compatible, while $\mathrm{NaCN}$ is highly toxic [5-8]. Chitosan has found successful application in a variety of industries in the past. These industries include but are not limited to wastewater treatment [9], agriculture, food industry [10, 11], and textile industry $[12,13]$. The depressing ability of chitosan in sulfides flotation was demonstrated during single and artificially mixed minerals flotation tests [5]. Chitosan has been reported to selectively depress the recovery of chalcopyrite $\left(\mathrm{CuFeS}_{2}\right)$ to $30 \%$ in a mixture of chalcopyrite and galena $(\mathrm{PbS})$ as reported by Huang et al. [6]. In single mineral flotation, chitosan depressed both galena and pyrite. However, during the flotation of pyrite-galena artificial mixtures, it was found that chitosan had a preferential adsorption on pyrite and thus it can selectively depress it. This was affirmed by observing the $68 \%$ recovery of galena compared to $23 \%$ recovery of pyrite at $\mathrm{pH} 4$ while in mixture [7]. These results demonstrated the competitive adsorption of chitosan on sulfide mineral surfaces. It should be kept in mind that all these observations were made in artificially mixed mineral samples. Motivated by these observations, this study was aimed to test the selective depressing ability of chitosan in real sulfide ores straight from the mine.

The overarching goal of this work was to test the possibility of replacing sodium cyanide by chitosan polymer as a selective pyrite depressant in the bulk flotation of complex sulfide ore sample containing galena $(\mathrm{PbS})$, chalcopyrite $\left(\mathrm{CuFeS}_{2}\right)$, sphalerite $(\mathrm{ZnS})$, pyrite $\left(\mathrm{FeS}_{2}\right)$, dolomite $\left(\mathrm{CaMg}\left(\mathrm{CO}_{3}\right)_{2}\right)$, and marcasite (a polymorph of pyrite). Flotation performance of the bulk ore sample in the presence of chitosan was compared with the flotation results obtained while using sodium cyanide as a depressant. The flotation performance was assessed in terms of \% recovery (\% yield) and $\%$ grade $(\%$ of $\mathrm{Pb}, \mathrm{Cu}, \mathrm{Fe}$, and $\mathrm{Zn}$ in concentrate products). The $\%$ recovery and the $\%$ grade of the concentrate products were studied as a function of polymer dosage added and the flotation time. Prior to flotation experiments, zeta potential measurements were carried out to examine the surface properties of different minerals at solid-water interface and to explore the interaction between chitosan polymer and minerals surfaces. The zeta potential studies were a premeasuring step of the potential of chitosan to selectively depress pyrite within the $\mathrm{pH}$ range studied.

\section{Experimental Section}

2.1. Materials and Reagents. Complex sulfide ore samples of Mississippi valley type were obtained from a mine located in North America. A full characterization study of mineral samples was conducted to reveal both qualitative and quantitative information about the crystalline phases within the sample as well as mineral associations, elemental distributions (assay), grain morphology, size distribution, and degree of liberation. Natural pure galena, pyrite, sphalerite, and chalcopyrite minerals were purchased from Ward's Scientific USA. In order to determine the purity of these minerals, Powder Xray Diffraction (PXRD) was conducted with a PANalytical X'Pert Pro Multipurpose Diffractometer (MPD) with $\mathrm{Cu} \mathrm{K} \alpha$ radiation $(\lambda=1.54 \AA)$ and a proportional counter detector equipped with a flat graphite monochromator. RIQAS software was used to analyze Rietveld refinement of the Xray diffraction patterns to estimate the phase composition. In order to find the instrumental broadening, a Gaussian correction was applied via NIST SRM 660a LaB6. It was observed that the samples were free of impurities. PXRD results revealed that the purity of the minerals was $>97 \%$. Each mineral was then crushed using a manual mortar/pestle grinder. The fine powder of each mineral was utilized in zeta potential measurements.

The chitosan polymer used in this work was of analytical grade. The polymer was purchased from ACROS, USA Inc., and used without further purification. Zeta potential of chitosan was recorded as $+7.11 \mathrm{mv}$. The molecular weight of the chitosan polymer used in this study was $800,000 \mathrm{Da}$ and its structure is given in Figure 1.

Hydrochloric acid and sodium hydroxide (Fisher scientific, USA) were used as $\mathrm{pH}$ modifiers. Sodium isopropyl xanthate was used as a collector while sodium cyanide and zinc sulphate were used as depressants. All of these reagents were purchased from Fisher Scientific, USA. 4-Methyl-2pentanol (MIBC) was purchased form ACROS, USA Inc., and was used as a frother. All flotation reagents were used without 


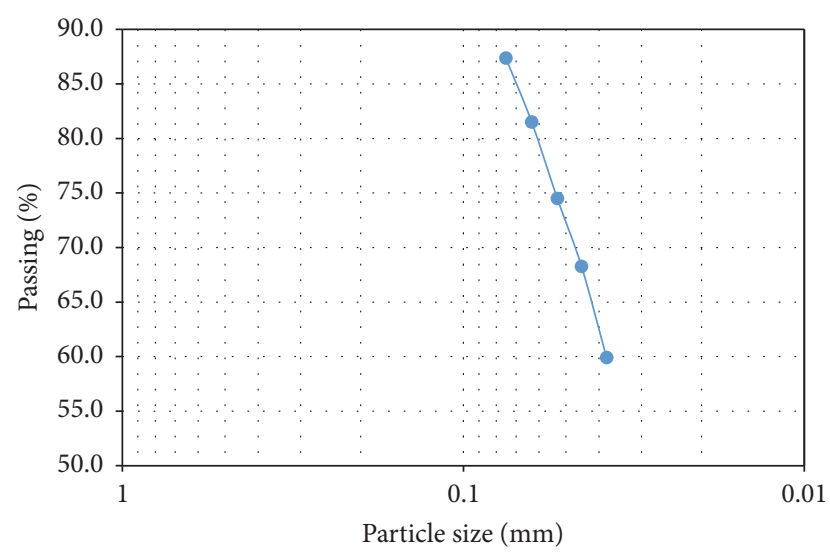

FIGURE 2: Particle size distribution of the flotation feed.

further purification. Tap water was used throughout the tests unless otherwise stated.

2.2. Preparation of Flotation Feed. The as received run-ofmine ore samples were crushed using a laboratory scale Jaw and cone crushers. Homogenized crushed ore was sealed in air tight plastic bags and stored in a refrigerator at $-10^{\circ} \mathrm{C}$ to avoid ore oxidation. A batch rod mill was used to reduce the ore to a size of $P_{80}=58$ microns. The mill that was used to achieve this was a stainless steel rod mill. The mill had an internal diameter of $20.16 \mathrm{~cm}$ and length of $25.4 \mathrm{~cm}$ and was equipped with 21 steel rods.

\subsection{Characterization of Flotation Feed}

2.3.1. Particle Size Distribution. The composite particle size distribution as determined by sieve analysis is shown in Figure 2. Screens of 200, 230, 270, 325, and 400 US mesh were used for sieving. The sieves are usually nested in order of decreasing size from the top to the bottom and the sample is placed on the top sieve. Sieves were shaken in a mechanical shaker for the time determined by the American Society for Testing and Materials (ASTM) protocols to provide complete separation for the sieve shaker being used. The composite particle size distribution $P_{80}$ of the flotation feed was approximately 58 microns.

2.3.2. Modal Analysis. The Mineralogical composition of the feed as determined by Mineral Liberation Analysis (MLA) is provided in Figure 3. MLA data was obtained using the XBSE method where the acquired backscattered electron (BSE) image is used to differentiate the mineral phases based on the gray level as the gray level intensity varies, dependent on the phase composition. The acquired X-ray spectrum obtained from each phase was compared to the X-ray mineral database to qualitatively determine mineral phases and the surface area data for each mineral was used for quantitative determination of the minerals identified. Samples were sent to the Center for Advanced Mineral \& Metallurgical Processing (CAMP) in Montana Tech of the University of Montana, USA, for MLA analysis.

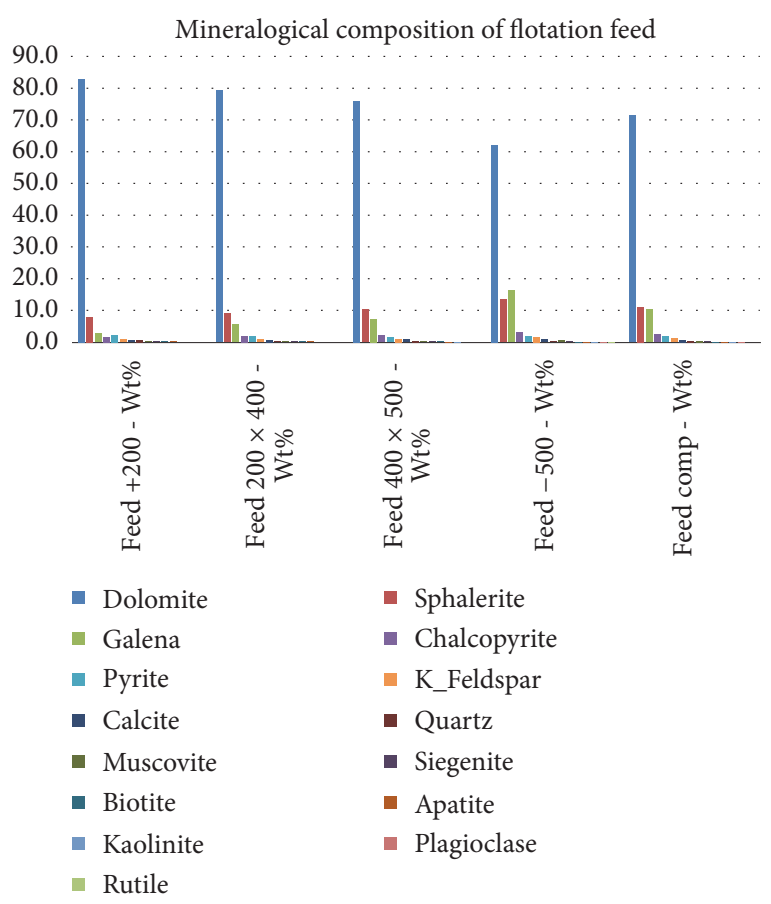

FIGURE 3: Mineralogical composition of flotation feed in different size fractions.

MLA results revealed that sulfide minerals constitute around $15-20 \%$ of the flotation feed. A large portion up to 70 to $80 \%$ of the feed consists of gangue minerals. Dolomite is the main gangue rock and needs to be separated from the valuable minerals. The second most abundant gangue mineral is pyrite which constitutes about $1-2 \%$ of the feed weight. Other gangue minerals like quartz, muscovite pyrite, and K-Feldspar are present in trace amounts. As shown in Figure 3, more than $70 \%$ of the galena (and lead) was contained in the -500 mesh fraction of the feed as was over half of the copper and zinc.

2.3.3. Grain Liberation. The classified MLA image in Figure 4 highlights a sulfide particle that displays associations between most of the sulfides found in the feed.

The percentage of surface liberation of chalcopyrite, galena, and sphalerite minerals was between 78 and $88 \%$ for particles containing $95-100 \%$ of the mineral of interest. Sphalerite had the highest liberation and chalcopyrite the lowest of these three sulfides. Lead is considered to be the most abundant valuable element present in the ore feed which constitutes $6 \%$ of the feed by weight. $\mathrm{Zn}$ is the second most abundant valuable element with a percentage weight of $5.5 \%$. Other notable elements are copper and iron with $0.7 \%$ and $2.27 \%$ of the feed by weight, respectively.

2.4. Batch Flotation Tests. Flotation tests were conducted using a Denver D-12 flotation machine (Figure 5) equipped with a 2 -liter tank and a 3.88-inch diameter impeller.

Feed slurry of $30 \%$ solids by weight was used in all experiments. Natural $\mathrm{pH}$ of 7.9 was maintained in all the 


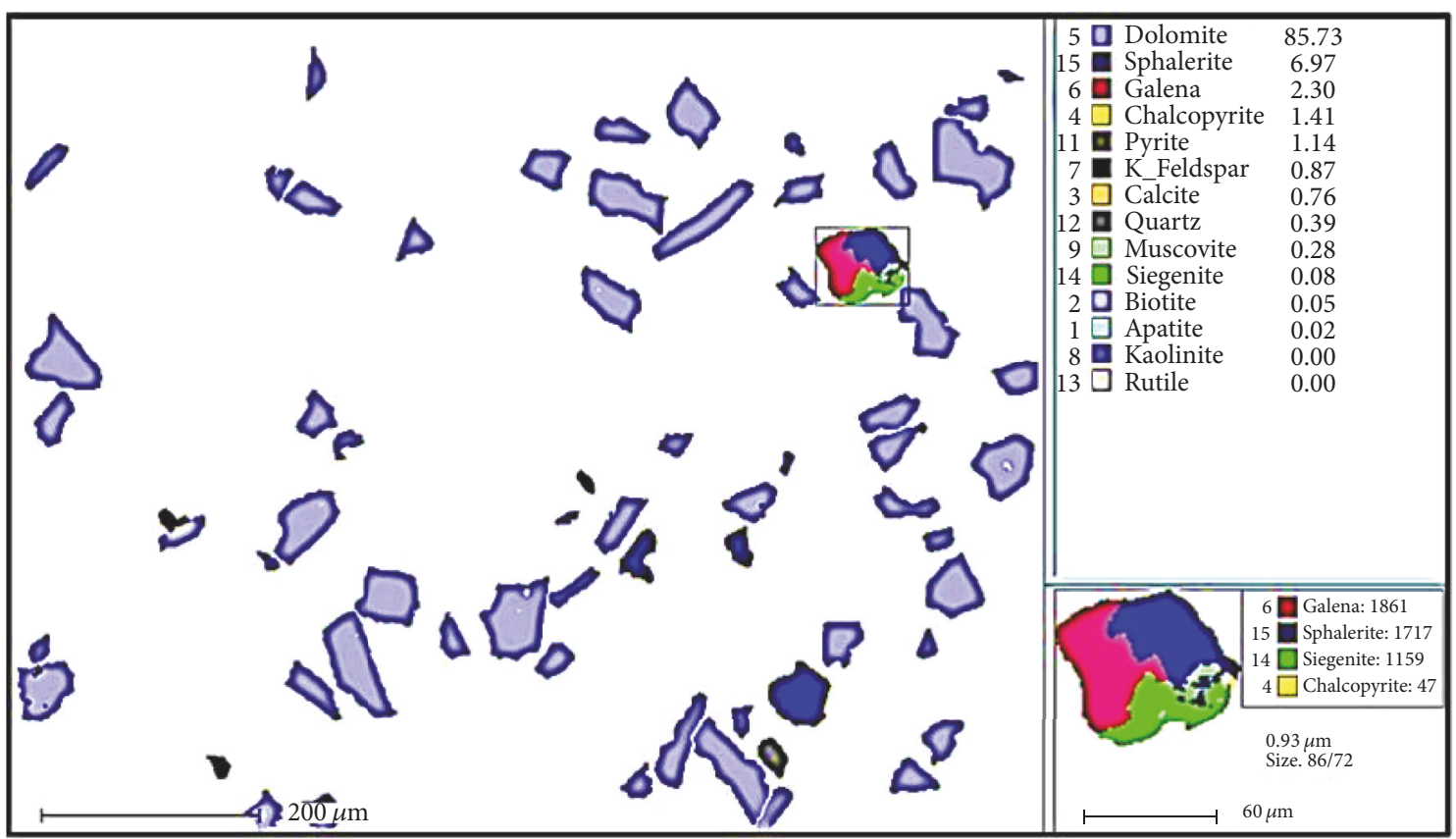

FIgURE 4: Classified MLA image of mineral associations found in the flotation feed. The inset shows minerals association within a grain of an approximate size of 60 microns (red: galena, blue: kaolinite, green: siegenite (cobalt-nickle sulfide), yellow: chalcopyrite, and navy: sphalerite).

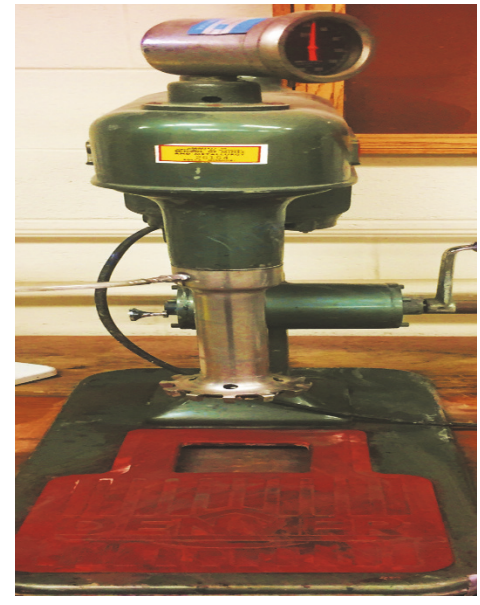

FIGURE 5: Denver flotation cell used in the current study.

flotation tests. Depressants (polymers, sodium cyanide, and zinc sulphate) were added first followed by the addition of xanthate collector. Frother was the last reagent to be added. Dosages of sodium cyanide, zinc sulphate, sodium isopropyl xanthate, and MIBC were kept the same in all flotation experiments at dosages of $2.26 \mathrm{~g} / \mathrm{ton}, 680 \mathrm{~g} / \mathrm{ton}, 317 \mathrm{~g} / \mathrm{ton}$, and $470 \mathrm{~g} /$ ton of ore, respectively, unless otherwise stated. Agitator was set at a rotation rate of 1000 RPM. Air flow rate was kept at 6 liter/min. Agitator speed and airflow rate were also kept constant during all flotation experiments. These parameters were found to be optimum through preliminary test runs.
Four sets of flotation tests were carried out. In the first set, no depressants were used and the ore was floated in the presence of the collector and the frother as the only reagents. Second set of flotation experiments was performed using conventional depressants sodium cyanide and zinc sulphate. Third set of flotation experiments was carried out using chitosan as the only depressant. Four different dosages $50 \mathrm{~g} /$ ton, $100 \mathrm{~g} /$ ton, $300 \mathrm{~g} / \mathrm{ton}$, and $500 \mathrm{~g} /$ ton of chitosan were tested. In the fourth and last set, $\mathrm{NaCN}$ was tested at dosages of $50 \mathrm{~g} /$ ton to be compared to the chitosan over the same dosage amounts. The dosages of all the reagents used are given in Table 1.

After flotation, both the froth products (concentrates) and tailings were collected, dried, weighed, and assayed for $\mathrm{Cu}, \mathrm{Pb}, \mathrm{Zn}$, and $\mathrm{Fe}$ contents. The elemental analysis of the concentrate and tailings products was calculated using Scanning Electron Microscopy equipped with EnergyDispersive X-ray Spectroscopy (SEM-EDS). Various products obtained from flotation process were pressed into 0.5 inch diameter pellets using 3851-0 Carver Hydraulic press (Carver Inc Wabash, USA). These pellets were coated with goldpalladium powder using a sputter-coater (Hitachi E-1030). After coating, Energy-Dispersive X-ray Spectroscopy (EDS) analysis of the samples was carried out using Hitachi Model S-4700 field-emission microscope. Accelerating voltage was kept at $25 \mathrm{kV}$, Emission current at $10.00 \mu \mathrm{Amp}$, working distance of $12 \mathrm{~mm}$, and magnification at 400x. Results of the EDS analysis were gathered and analyzed by EDAX Inc. Genesis software.

Metal recoveries were calculated using dry weights of concentrates and tailing products using (1), where $C$ and $T$ are dry weights of the concentrate and tailing products, 
TABLE 1: Reagent used in the different sets of flotation experiments.

\begin{tabular}{lccccc}
\hline Experiment sets & $\begin{array}{c}\text { Sodium cyanide } \\
\text { g/ton }\end{array}$ & $\begin{array}{c}\text { Zinc sulfate } \\
\text { g/ton }\end{array}$ & $\begin{array}{c}\text { Sodium isopropyl xanthate } \\
\text { g/ton }\end{array}$ & $\begin{array}{c}\text { MIBC } \\
\text { g/ton }\end{array}$ & $\begin{array}{c}\text { Chitosan } \\
\text { g/ton }\end{array}$ \\
\hline First & 0 & 0 & 317 & 470 & 0 \\
Second & 2.26 & 680 & 317 & 470 & 0 \\
Third & 0 & 0 & 317 & 470 & $50,100,300,500$ \\
Fourth & 50 & 680 & 317 & 470 & 0 \\
\hline
\end{tabular}

respectively; $c$ and $t$ are \% of metals in concentrates and tailings as determined by SEM-EDS.

$$
\text { Recovery }=\frac{C c}{(C c+T t)} * 100 \% \text {. }
$$

2.5. Zeta Potential Measurement. The single mineral samples purchased from Wards Science were ground in an agate mortar. The mineral suspensions containing $0.05 \%$ solids in $1 \mathrm{mmol} / \mathrm{L} \mathrm{KCl}$ were sonicated for $15 \mathrm{~min}$ then allowed to settle for $5-10 \mathrm{~min}$. The upper portion of the supernatant was considered for the zeta potential measurements. The $\mathrm{pH}$ of all the suspensions was maintained at a value of 7.9. Zeta potential measurements were carried out using Zetasizer Nano ZS, ZEN3600, by Malvern Instruments Limited., Worcestershire, UK. Laser Doppler Microelectrophoresis was used to measure the velocity of mineral particles in the solution under an electric field. This velocity was measured using a laser interferometric technique called M3-PALS (Phase analysis Light Scattering). Smoluchowski model was then used to calculate zeta potential.

\section{Results and Discussion}

In this study the performance of the polymer chitosan as a selective pyrite depressant was investigated. In this regard, the recoveries of lead, copper, zinc, and iron elements were calculated in the froth products in the presence of chitosan at different dosages and compared with the recoveries of these elements when $\mathrm{NaCN}$ was used as a depressant. Recovery values were in turn compared with the results obtained when flotation was conducted without any depressants.

3.1. Zeta Potential Measurements. Zeta potential measurements were conducted on mineral suspensions with and without the addition of chitosan polymer to fundamentally explore and compare the surface properties and interaction mode of the polymer with galena, pyrite, chalcopyrite, and sphalerite. As shown in Figure 6, the particles of all the minerals were negatively charged at $\mathrm{pH} 7.9$ with pyrite having the largest negative charge value of $\sim-36 \mathrm{mV}$ compared with $\sim-20 \mathrm{mV},-7.5 \mathrm{mV}$, and $-18.5 \mathrm{mV}$ for chalcopyrite, galena, and sphalerite, respectively. These values are consistent with the values reported in literature at similar $\mathrm{pH}$ range [14, 15]. Addition of chitosan polymer to mineral suspensions resulted in increasing the values of surface charge to more positive values for all minerals. This observation indicated that chitosan was adsorbed on the surface of these minerals.

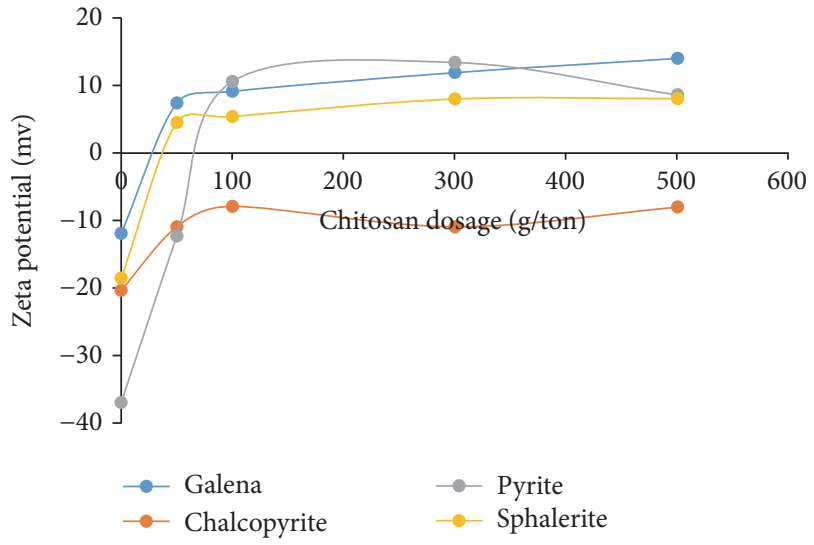

FIGURE 6: Zeta potential measurements of mineral suspensions as a function of chitosan dosage at $\mathrm{pH} \sim 8$.

For example, at $500 \mathrm{~g} /$ ton of polymer, the zeta potential value of galena, chalcopyrite, pyrite, and sphalerite increased from $-7.5,-20,-36$, and $-18.5 \mathrm{mV}$ to $+12,+5,-10$, and $+4.5 \mathrm{mV}$, respectively. Figure 6 also exhibited that as the dosage of the polymer increased, the measured value of surface charge of a specific mineral becomes more positive. For example, increasing the chitosan dosage from $50 \mathrm{~g} / \mathrm{t}$ to $100 \mathrm{~g} / \mathrm{t}$ resulted in increasing the value of zeta potential of pyrite suspensions from -12.3 to $+13.4 \mathrm{mV}$, respectively. As expected and shown in Figure 6, chitosan polymer has stronger interaction with pyrite and sphalerite minerals as compared to galena and chalcopyrite. At $100 \mathrm{~g} / \mathrm{t}$ of chitosan, the value of zeta potential of pyrite suspension dramatically shifted from -36 to $+10 \mathrm{mV}$ while in the case of galena, the value of zeta potential slightly shifted from -7.5 to $-1.9 \mathrm{mV}$. Moreover, the interaction of chitosan with sphalerite and chalcopyrite surfaces is stronger in comparison with galena. For example, the zeta potential value of chalcopyrite suspensions was shifted from -20 to $-8 \mathrm{mV}$ at $100 \mathrm{~g} / \mathrm{t}$ of chitosan. At the same chitosan dosage, zeta potential of sphalerite increased from -18.5 to +5.4 . The results were very consistent with what was previously published in literature when chitosan was used in the flotation of model sulfide mineral suspensions [1, 5-7, 13-16]. The adsorption mechanism of chitosan on sulfide minerals has not been comprehensively explained yet. There are only few studies that attempted to examine the adsorption behavior and elucidate the selectivity of chitosan towards pyrite, chalcopyrite, and sphalerite compared to galena. In general, the interaction mechanism between chitosan and certain ion on mineral surfaces is due to chelation [17-19]. Both amino 
groups $\left(-\mathrm{NH}_{2}\right.$ and $\left.\mathrm{O}=\mathrm{C}-\mathrm{NH}_{2}\right)$ and the hydroxyl groups $(\mathrm{C}-\mathrm{OH})$ are anticipated to be the major binding sites for chitosan adsorption on mineral surfaces [20, 21]. It has been also reported that the adsorption capacity of chitosan and the consequent formation of polymer-ion complex can be influenced by many factors such as solution $\mathrm{pH}$ [22], physical type of chitosan, and the degree of deacetylation [23, 24]. $\mathrm{X}$-ray photoelectron spectroscopy was used to understand the selective adsorption of chitosan on chalcopyrite-galena mixtures as well as pyrite-galena mixtures [6]. In their work, Huang et al. compared the binding energy values of mineral surfaces before and after treatment with chitosan polymer. In the case of comparative adsorption of the chitosan on chalcopyrite versus galena, results indicated that chitosan adsorbed on both minerals with larger binding energy shift of amino groups in the case of chitosan-chalcopyrite system compared with chitosan-galena system. More binding energy shifts reflect a stronger adsorption of the polymer on mineral surface. Result suggested that in the case of chalcopyrite, both amine group and amide group in the chitosan molecules are involved with the formation of ammonium (protonated amine) complex which was absent in the case of galenachitosan system. The larger binding energy shift of amino groups and the appearance of ammonium complex on the surface of chalcopyrite suggest chemical adsorption rather than a physisorption which was the proposed mode of adsorption of chitosan on galena. Similar surface studies using XPS were performed on chitosan/pyrite system. Results suggested the formation of protonated amine on the surface of pyrite after chitosan adsorption with large binding energy shift of amine groups in chitosan molecules from $399.5 \mathrm{eV}$ before adsorption to $399.8 \mathrm{eV}$ after adsorption suggested that chemical adsorption rather than physisorption may have occurred between chitosan and pyrite surface. Other studies [25] suggested that the preferential adsorption of chitosan on different mineral surfaces is related to the electron affinity of constituent metals. The higher the electron affinity of the constituent metal, the stronger the interaction between the amine groups in chitosan molecules and the mineral surface. Thus, chitosan adsorbs more preferentially on chalcopyrite surface compared to galena since the electron affinities of copper ions and iron ions are larger than galena.

\subsection{Flotation Experiments}

3.2.1. Influence of Chitosan Dosage on the Flotation Performance Sulfide Minerals. Four different dosages of chitosan polymer were used in the flotation experiments: 50, 100, 300 , and $500 \mathrm{~g} / \mathrm{ton}$. As reported in literature, these dosages were used when polymers such as polyacrylamide (PAM) and its derivatives were applied in sulfide mineral flotation [26]. Results were compared with the flotation results in presence and absence of the optimum dosage of conventional depressants, $\mathrm{NaCN}$. The optimum dosage of $\mathrm{NaCN}$ was obtained by performing a series of experiments using a wide range of dosages (1-100 g/ton). The optimum dosage of $\mathrm{NaCN}$ was found to be $2.26 \mathrm{~g} / \mathrm{ton}$. At this dosage, $\mathrm{NaCN}$ was able to selectively depress pyrite while keeping the recovery of other sulfides relatively high. At a dosage of

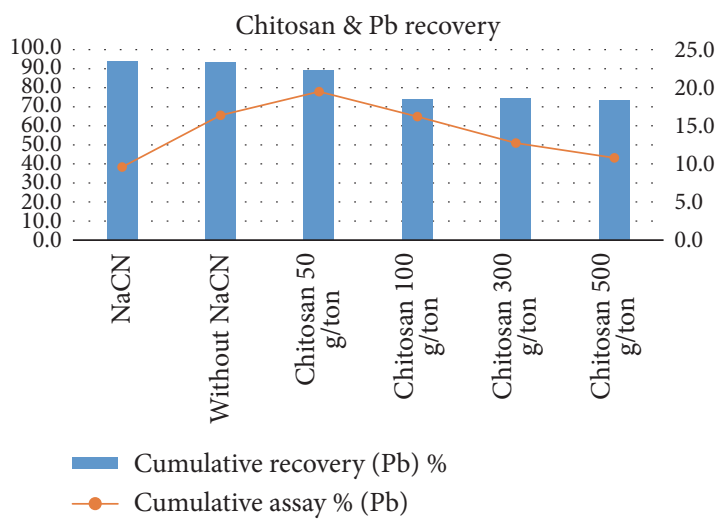

FIgURE 7: Lead recovery and concentrate grade as a function of chitosan dosage in comparison with $\mathrm{NaCN}$ depressant.

$50 \mathrm{~g} / \mathrm{ton}$, chitosan did reduce the recovery of lead by $4.8 \%$ (Figure 7) and that of copper by $8.8 \%$ (Figure 8 ) as compared to conventional depressant $\mathrm{NaCN}$, which was not desirable as bulk flotation of chalcopyrite and galena was the major focus of this experiment. However, as shown in Figure 9. Chitosan was able to depress iron recovery more than 5.6\% as compared to the conventional depressant $\mathrm{NaCN}$ at its optimum dosage. As for zinc, Figure 10 shows that, at $50 \mathrm{~g} / \mathrm{ton}$ of chitosan, the recovery of zinc in the froth increased by $40 \%$ compared to $\mathrm{NaCN}$ at its optimum dosage which is undesirable in the differential flotation of sulfide minerals where lead and copper sulfides are floated in the first flotation stages while sphalerite is depressed. Results also revealed that increasing the dosage to $100 \mathrm{~g} /$ ton and up caused a decrease in the recovery of both galena and chalcopyrite. As for the enrichment of minerals in the concentrates, at $50 \mathrm{~g} / \mathrm{ton}$ of chitosan, the concentrate grade of galena increased to $20 \%$ compared to $10 \%$ when $\mathrm{NaCN}$ was used. However, the concentrate grade of chalcopyrite and pyrite slightly decreased from $2.7 \%$ and $4.2 \%$ with $\mathrm{NaCN}$ to $2.2 \%$ and $3 \%$ with $50 \mathrm{~g} / \mathrm{t}$ chitosan, respectively. As for pyrite, it is interesting to see that increasing the polymer dosage to $100 \mathrm{~g} / \mathrm{t}$ and higher resulted in an increase in the recovery of pyrite in the concentrate which might be due to competitive adsorption at higher dosages of polymer. Figure 11 shows the results of flotation experiments with optimum chitosan dosage of $50 \mathrm{~g} /$ ton with equivalent $\mathrm{NaCN}$ dosage. It can be clearly seen that $\mathrm{NaCN}$ at a dosages of $50 \mathrm{~g} /$ ton greatly reduced the recovery of valuable metals such as copper and lead along with zinc and iron. As a result, keeping in mind the economics and efficiency of flotation process, an optimum dosage of $2.26 \mathrm{~g} /$ ton of $\mathrm{NaCN}$ was found to be most feasible to be compared to chitosan dosages of 50 to $500 \mathrm{~g} / \mathrm{ton}$.

In general, the preferential adsorption of chitosan on pyrite and chalcopyrite is due to the ability of the polymer to chemically bond to the mineral surface which results in stronger adsorption compared to galena. It was proposed that [16] the amine groups and the hydroxyl group in the chitosan structure (Figure 1) can react with the mineral surfaces and form a stable complex through chemisorption mechanism which resulted in its stronger flotation depression 


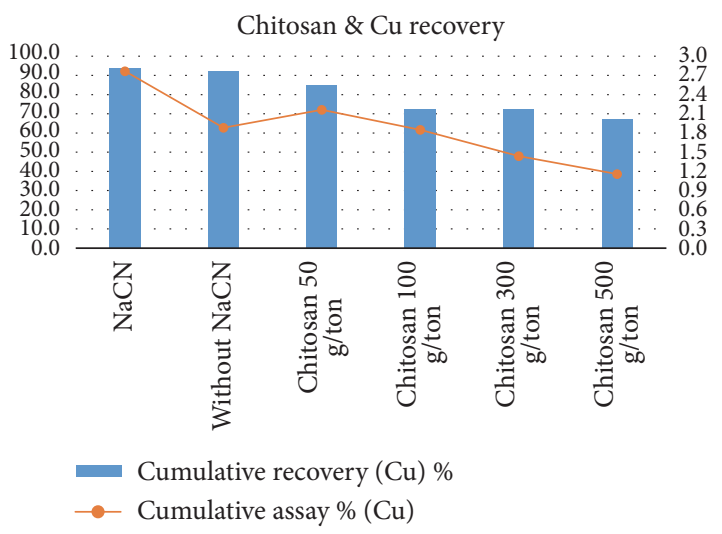

FIGURE 8: Copper recovery and concentrate grade as a function of chitosan dosage in comparison with $\mathrm{NaCN}$ depressant.

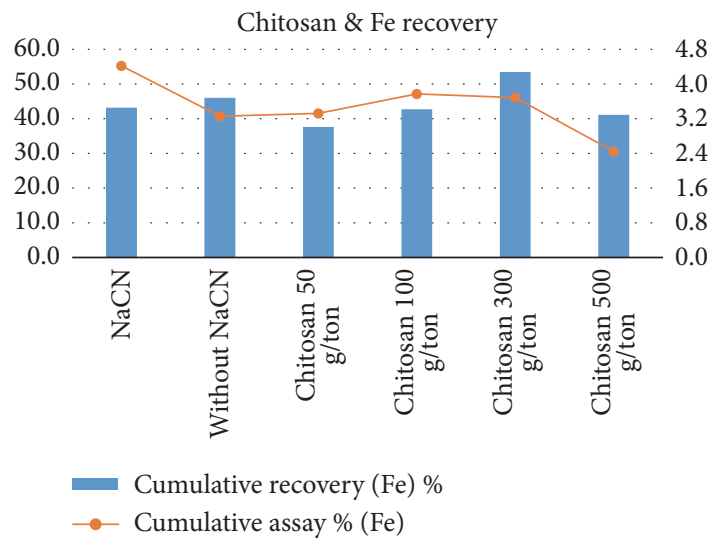

FIGURE 9: Iron recovery and concentrate grade as a function of chitosan dosage in comparison with $\mathrm{NaCN}$ depressant.

compared to galena. The adsorption of chitosan polymers on galena is anticipated to physisorption mechanism through hydrophobic interactions between the mineral surface and the amide group of chitosan molecules. Results obtained from the flotation experiments conducted in this study are consistent with model mineral flotation tests reported by Huang, where chitosan was found to be a selective depressant for sphalerite and pyrite in galena-sphalerite and galenapyrite artificial mixtures [5]. Moreover, flotation results were consistent with zeta potential studies carried out in this work (Figure 6) which show preferential adsorption of chitosan on sphalerite and pyrite as compared to chalcopyrite and galena. It can therefore be concluded that chitosan can be introduced as a depressant for sphalerite and pyrite in bulk flotation of chalcopyrite and galena.

3.2.2. Influence of Flotation Time on the Recovery of Galena, Chalcopyrite, and Pyrite in the Presence of Chitosan Polymer. At an optimum dosage of $50 \mathrm{~g} /$ ton of chitosan, froth products were collected after $0,2,4$, and 8 mins of flotation. It was observed that after 4 minutes of flotation $86.3 \%$ of lead, $79.6 \%$ of copper, and $33 \%$ of iron were recovered as shown in Figure 12. Doubling the flotation time to 8 minutes increased

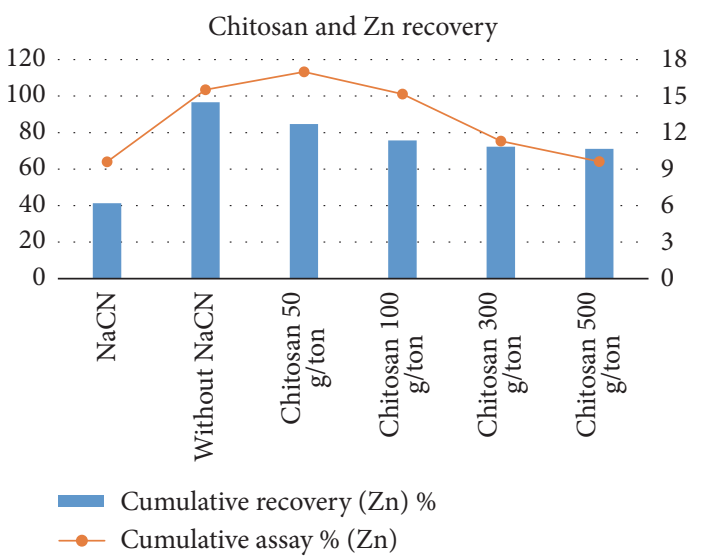

FIgURE 10: Zinc recovery and concentrate grade as a function of chitosan dosage in comparison with $\mathrm{NaCN}$ depressant.

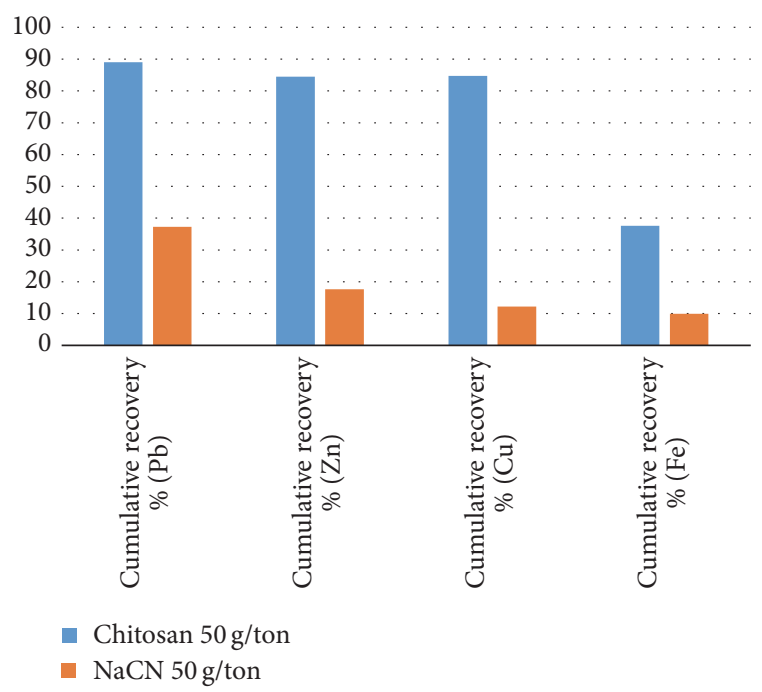

FIGURE 11: Comparison of flotation recoveries of different sulfide minerals in the concentrate products when using either chitosan or $\mathrm{NaCN}$ at equivalent dosage of of $50 \mathrm{~g} / \mathrm{ton}$.

recovery of lead and copper only by 2.6 and $5 \%$, respectively. However, the undesirable recovery of $\mathrm{Fe}$ in the product increased by $4.5 \%$. This shows that most of lead and copper are floated in the initial 4 minutes of flotation. After 4 minutes selective flotation ceases and all minerals are recovered at the same rate. It therefore seems that depending upon the plant economics, four minutes of flotation time may be regarded as optimum.

\section{Conclusions}

The objective of this study was to investigate the potential of replacing the toxic depressant $\mathrm{NaCN}$, used as a selective pyrite depressant in the flotation of sulfide minerals, by the biodegradable chitosan polymer. Bulk flotation tests of sulfide mineral samples containing galena, chalcopyrite, pyrite, and sphalerite were carried out in laboratory scale Denver flotation cell to compare the depression capability of 


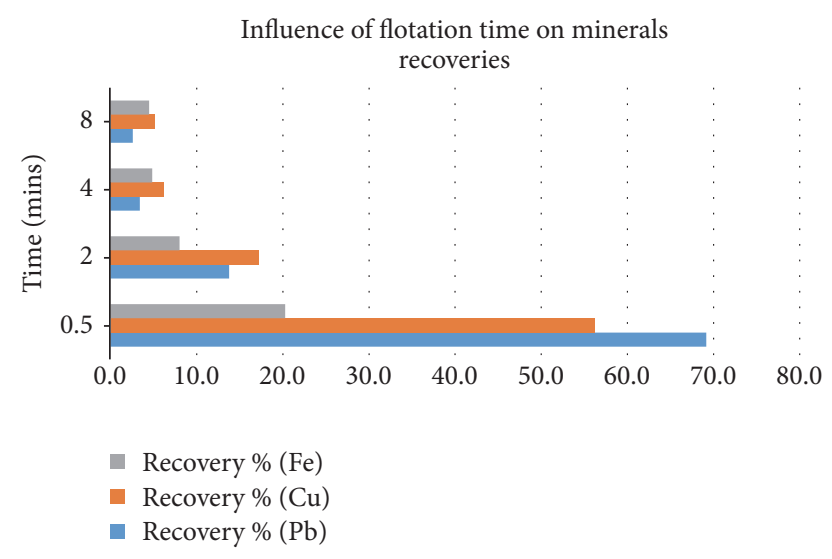

FIGURE 12: Influence of flotation time on flotation recoveries of galena, pyrite, and chalcopyrite at a chitosan's dosage of $50 \mathrm{~g} / \mathrm{ton}$.

$\mathrm{NaCN}$ and chitosan polymer, separately. It was found that chitosan was effective mostly in depressing pyrite minerals. Chitosan depressed 5.6\% more pyrite as compared to conventional depressants $(\mathrm{NaCN})$ at its optimum dosage of $2.26 \mathrm{~g} / \mathrm{ton}$. It was however noted that, at higher dosages, chitosan depressed chalcopyrite and galena which was not desired in this case. The optimum dosage of chitosan was $50 \mathrm{~g} / \mathrm{ton}$. At this dosage, galena had the highest recovery while pyrite had the lowest recovery. It was also found that using equivalent dosages of chitosan and $\mathrm{NaCN}$ at $50 \mathrm{~g} /$ ton (optimum dosage of chitosan), $\mathrm{NaCN}$ dramatically depressed all valuable minerals by $>50 \%$.

Findings obtained from zeta potential measurements were consistent with those obtained from flotation test. Zeta potential measurements of galena, chalcopyrite, sphalerite, and pyrite suspensions before and after chitosan addition revealed that chitosan has stronger and preferential interaction with pyrite and sphalerite surface as indicated by the dramatic shift in the zeta values of the mineral before and after the addition of chitosan. This study shows that chitosan may have a bright prospect to be used in sulfide mineral flotation as pyrite depressant.

\section{Conflicts of Interest}

The authors declare that they have no conflicts of interest.

\section{References}

[1] P. Huang, L. Wang, and Q. Liu, "Depressant function of high molecular weight polyacrylamide in the xanthate flotation of chalcopyrite and galena," International Journal of Mineral Processing, vol. 128, pp. 6-15, 2014.

[2] O. Molatlhegi and L. Alagha, "Ash Depression in Fine Coal Flotation Using a Novel Polymer Aid," International Journal of Clean Coal and Energy, vol. 05, no. 04, pp. 65-85, 2016.

[3] N. Magdalinovic, "Cyanide elimination from lead-zinc flotation," European Journal of Mineral Processing and Environmental Protection, vol. 4, no. 1, pp. 30-35, 2004.
[4] J.-F. Zhang, Y.-H. Hu, D.-Z. Wang, and J. Xu, "Depressing effect of hydroxamic polyacrylamide on pyrite," Journal of Central South University of Technology, vol. 11, no. 4, pp. 380-384, 2004.

[5] P. Huang, hitosan in differential flotation of base metal sulfides, University of Alberta, 2013.

[6] P. Huang, M. Cao, and Q. Liu, "Using chitosan as a selective depressant in the differential flotation of $\mathrm{Cu}-\mathrm{Pb}$ sulfides," International Journal of Mineral Processing, vol. 106-109, pp. 8-15, 2012.

[7] P. Huang, M. Cao, and Q. Liu, "Selective depression of pyrite with chitosan in $\mathrm{Pb}-\mathrm{Fe}$ sulfide flotation," Minerals Engineering, vol. 46-47, pp. 45-51, 2013.

[8] Y. Xiang, Carboxymethyl Chitosan as a Selective Depressant in Differential Flotation of Galena and Chalcopyrite, University of Alberta, 2015.

[9] M. N. V. Ravi Kumar, "A review of chitin and chitosan applications," Reactive \& Functional Polymers, vol. 46, no. 1, pp. 1-27, 2000.

[10] G. Crini and P.-M. Badot, "Application of chitosan, a natural aminopolysaccharide, for dye removal from aqueous solutions by adsorption processes using batch studies: a review of recent literature," Progress in Polymer Science, vol. 33, no. 4, pp. 399447, 2008.

[11] G. Egger, D. Cameron-Smith, and R. Stanton, "The effectiveness of popular, non-prescription weight loss supplements," Medical Journal of Australia, vol. 171, no. 11-12, pp. 604-608, 1999.

[12] Y.-S. Chung, K.-K. Lee, and J.-W. Kim, "Durable Press and Antimicrobial Finishing of Cotton Fabrics with a Citric Acid and Chitosan Treatment," Textile Research Journal, vol. 68, no. 10, pp. 772-775, 1998.

[13] D. Jocić, M. R. Julià, and P. Erra, "Application of a chitosan/nonionic surfactant mixture to wool assessed by dyeing with a reactive dye," Journal of the Society of Dyers and Colourists, vol. 113, no. 1, pp. 25-31, 1997.

[14] B. Feng, Y. Lu, and X. Luo, "The effect of quartz on the flotation of pyrite depressed by serpentine," Journal of Materials Research and Technology, vol. 4, no. 1, pp. 8-13, 2015.

[15] Z.-J. Piao, D.-Z. Wei, Z.-L. Liu, W.-G. Liu, S.-L. Gao, and M.-Y. Li, "Selective depression of galena and chalcopyrite by O,O-bis(2,3- dihydroxypropyl) dithiophosphate," Transactions of Nonferrous Metals Society of China (English Edition), vol. 23, no. 10, pp. 3063-3067, 2013.

[16] P. Huang, M. Cao, and Q. Liu, "Adsorption of chitosan on chalcopyrite and galena from aqueous suspensions," Colloids and Surfaces A: Physicochemical and Engineering Aspects, vol. 409, pp. 167-175, 2012.

[17] W. S. Wan Ngah, L. C. Teong, and M. A. K. M. Hanafiah, "Adsorption of dyes and heavy metal ions by chitosan composites: a review," Carbohydrate Polymers, vol. 83, no. 4, pp. 14461456, 2011.

[18] A. Burke, E. Yilmaz, N. Hasirci, and O. Yilmaz, "Iron(III) ion removal from solution through adsorption on chitosan," Journal of Applied Polymer Science, vol. 84, no. 6, pp. 1185-1192, 2002.

[19] C. Gerente, V. K. C. Lee, P. Le Cloirec, and G. McKay, "Application of chitosan for the removal of metals from wastewaters by adsorption-mechanisms and models review," Critical Reviews in Environmental Science and Technology, vol. 37, no. 1, pp. 41127, 2007.

[20] S. Sun and A. Wang, "Adsorption properties and mechanism of cross-linked carboxymethyl-chitosan resin with $\mathrm{Zn}(\mathrm{II})$ as template ion," Reactive and Functional Polymers, vol. 66, no. 8, pp. 819-826, 2006. 
[21] X. H. Wang, Y. Du, and H. Liu, "Preparation, characterization and antimicrobial activity of chitosan-Zn complex," Carbohydrate Polymers, vol. 56, no. 1, pp. 21-26, 2004.

[22] E. Guibal, "Uranium sorption by glutamate glucan: A modified chitosan Part II: Kinetic studies," WATER SA-PRETORIA, no. Part II, pp. 119-119, 1993.

[23] G. L. Rorrer, T.-Y. Hsien, and J. D. Way, "Synthesis of porousmagnetic chitosan beads for removal of cadmium ions from waste water," Industrial and Engineering Chemistry Research, vol. 32, no. 9, pp. 2170-2178, 1993.

[24] I. M. Vold, K. M. Vårum, E. Guibal, and O. Smidsrød, "Binding of ions to chitosan - Selectivity studies," Carbohydrate Polymers, vol. 54, no. 4, pp. 471-477, 2003.

[25] R. G. Parr and R. G. Pearson, "Absolute hardness: companion parameter to absolute electronegativity," Journal of the American Chemical Society, vol. 105, no. 26, pp. 7512-7516, 1983.

[26] A. Boulton, D. Fornasiero, and J. Ralston, "Selective depression of pyrite with polyacrylamide polymers," International Journal of Mineral Processing, vol. 61, no. 1, pp. 13-22, 2001. 

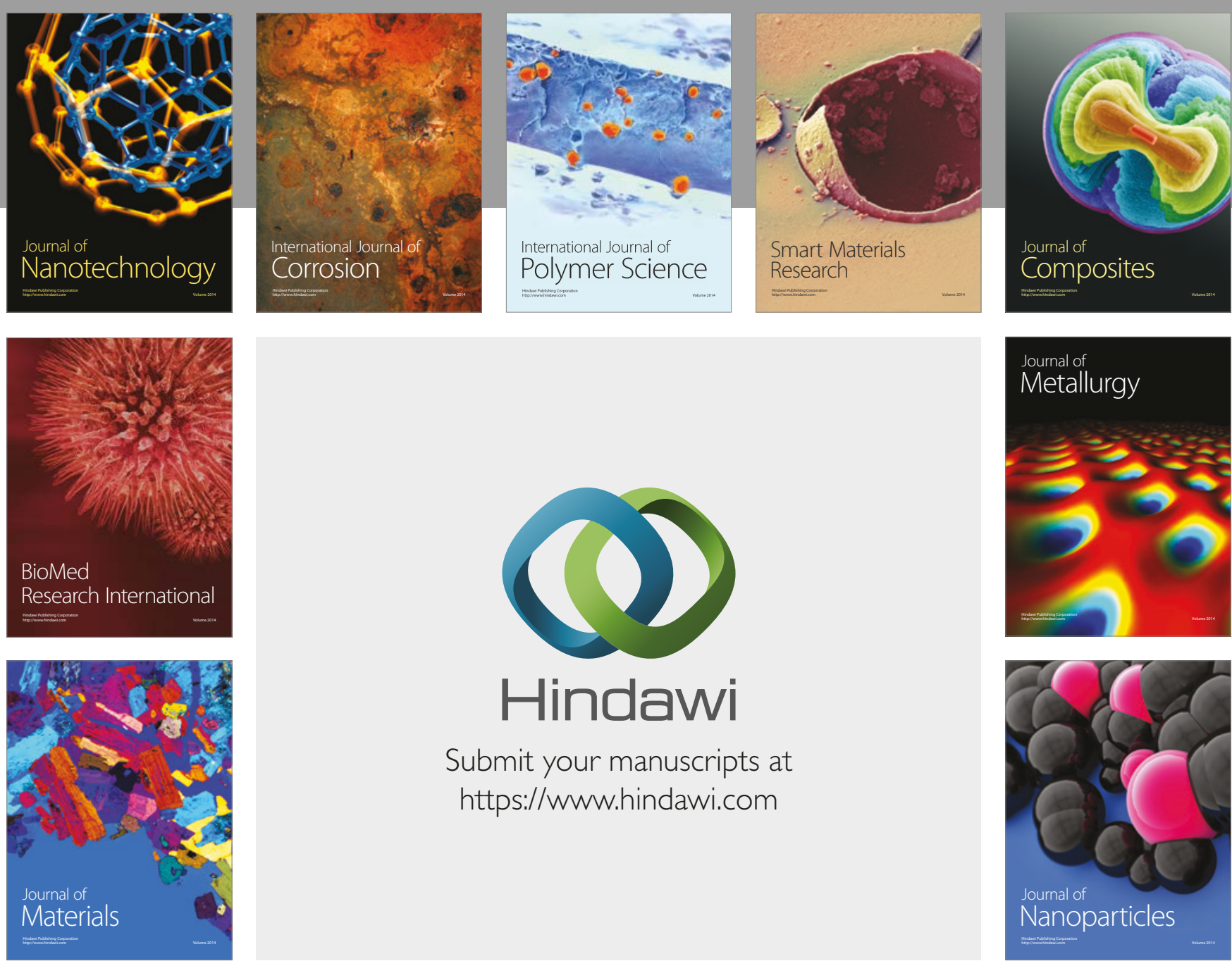

\section{Hindawi}

Submit your manuscripts at

https://www.hindawi.com
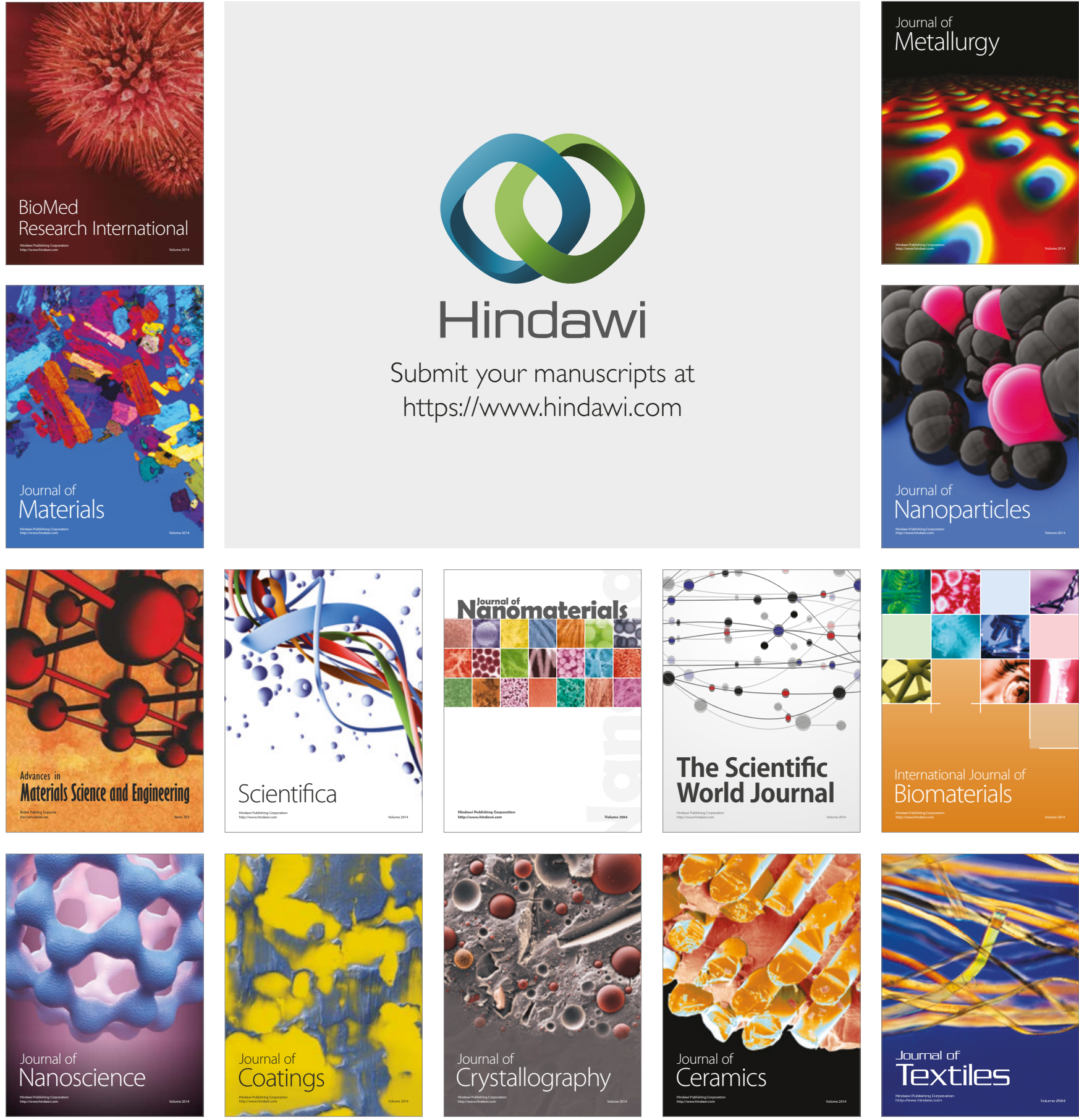

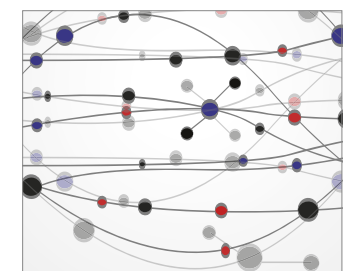

The Scientific World Journal
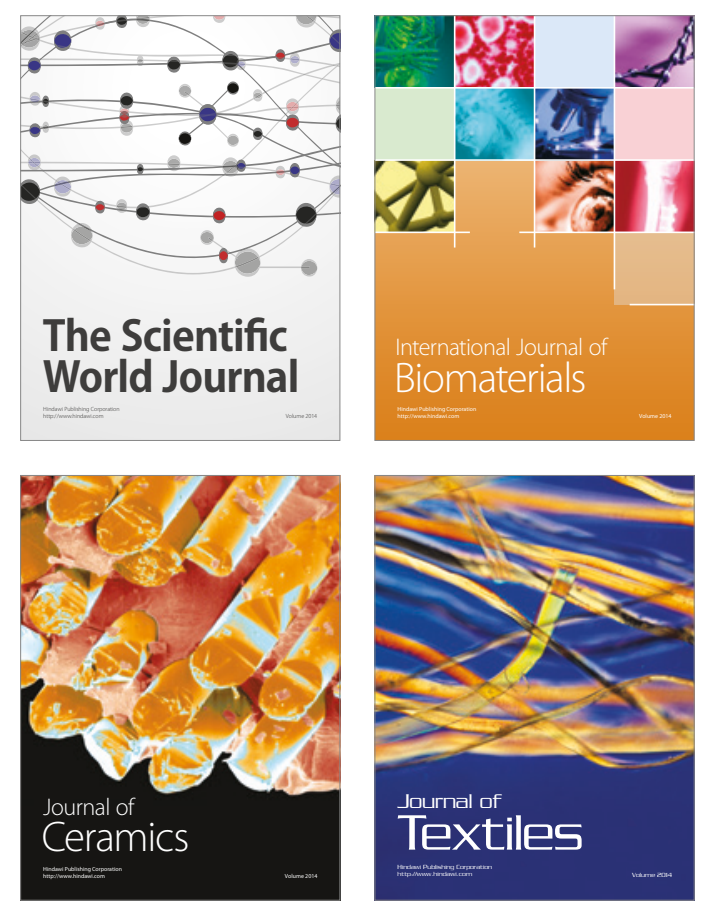